\title{
Sobre a escrita etnográfica, ética e perícia
}

\section{Ilka Boaventura Leite}

Pesquisadora CNPq / Unıversıdade Federal de Santa Catarına Florıanopolıs Brasıl llka@cfh ufsc br

primeira vez que visiteı Silvio Coelho dos Santos em sua casa na
Agronômıca, em 1982, ele tinha acabado de fazer um parecer técnico sobre a construção de uma barragem em terras indígenas No calor desta experiêncıa/escrita, dıscorreu detalhadamente sobre certos "dılemas etıcos" perante aquilo que consıderava um ato espúrıo de expropriação injusta dos recursos ambientais dos povos índıos em Santa Catarına Como não se posıcıonar dıante da imınência de um novo genocídıo dısfarçado em projeto de desenvolvımento? Era este o dilema ao qual respondia com furmeza e contundêncıa, com uma vısão convicta sobre o papel da Antropologıa numa sıtuação de conflito de interesses como a que se apresentava Diante de tão declarado pragmatısmo consonante à possıbılıdade da medıação, Sılvıo passou a apresentar desde então, e em diversas circunstâncıas, sua posıção sobre o papel da Antropologia em situações de conflito, em seus relatórıos, artıgos e lıvros (Santos, 1983, 1989 2007) e também nos acalorados debates públıcos e conferêncıas que partıcıpou

Fol assım que, em março de 2007, ele se apresentou com toda a sua autorıdade de professor emérıto da UFSC, ex-presıdente e membro do conselho de etıca da Assocıação Brasıleıra de Antropologıa, para 
levantar duvidas sobre a formação e o tıpo de pesquisa de campo elaborada em forma de um "contra-laudo" por um historiador contratado pela ex-Imarıbo e atual empresa Iguaçu - Celulose e Papel S/A, situada em Campos Novos, SC As terras, objetos de disputas por maıs de 40 anos, estıveram sob a ıdentıfıcação no Instıtuto Nacıonal de Colonızação e Reforma Agrárıa (INCRA), onde foram citados entre outros, a empresa Iguaçu Essas terras foram descritas anteriormente em pesquisa etnografica realızada por Raquel Mombell para o projeto "O Acesso a terra e a cıdadanıa negra exproprıação e violêncıa, no limite dos dureitos (NUER/UFSC/CNPq) desenvolvido sob minha coordenação entre os anos de 1998-2006 A pesquisa etnografica inıcıou, de fato, em 1994 por Alejandro Labale para o Projeto "Plunetnicidade e Intolerâncıas relações interétnıcas no sul do Brasıl (NUER/ CNPq/ Fundação Ford)" tambem sob munha coordenação A documentação levantada e apresentada no parecer tecnico elaborado pelo NUER, em 2006, resumu mals de dez anos de pesquisa de campo etnografica e histórico-documental nos arquivos hustorıcos de Santa Catarına por equipe interdisciplinar composta por antropologos, hustorıadores e geografos

Em 2004, o Minısterıo Publico Federal - Procuradona de Joaçaba acolheu uma solıcıtação dos herdeıros em audıêncıa públıca realızada na Câmara de Vereadores de Campos Novos Após ouvrr, pruncupalmente os herdeuros dos ex escravos e com o apoio da Procuradorıa Jurídica da Fundação Cultural Palmares, este orgão instaurou o inquerıto civil publıco para averıguação das terras em dısputa A ultıma fase da pesquisa etnografica realızada pelo NUER para integrar o inquerito e o processo de regularızação fundıárıa das terras no INCRA ocupou maıs dois anos apos essa decada mencionada Seus resultados, publicados como relatorıo técnıco (Boletım Informatıvo do Nuer, 2006), indıcaram como terras dos ex-escravos todas aquelas descritas pelo testamento de 1867. cıtado na ação de divisão, que foı realızada na década de 1940, por um advogado e proprıtárıo de uma empresa de colonızação em Campos Novos

O relatorıo descreve como a referıda ação de divisão transferıu metade da area territorial para o advogado, a contragosto dos herdelros, que se viram desde então lıgados pelo direıto de herança negado 
Através de nova ação recolonızadora, o processo de dıvısão apagou dos regıstros cartorıaıs o ato de doação anterıor, varrındo assım para o subterrâneo da hıstórıa a exproprıação das terras doadas aos ex-escravos em testamento de 1867, ou seja, 21 anos antes da abolição do trabalho escravo no Brasıl O Relatorı do NUER concluıu que houve supressão dos dıreitos ja adquirıdos e apontou os indicıos da ação fraudulenta Os herdeiros, ao inves de herdar as terras perderam nas, e estas passaram em seguida ao mercado sendo adquirıdas pela referida empresa de celulose A empresa, antes mesmo de efetuar a compra, extraiu toda a mata natıva de araucarıas para em seguida a compra, plantar pınus elliotıs Em sua fase de instalação na fazenda Invernada dos Negros de Campos Novos, destınou um pequeno canteiro de terras varrıdas por agrotóxıcos para algumas famílias que resıstıram à completa salda da área

O NUER, em 1994, atendendo à solicitação da assocıação constıtuıda pelos herdeuros dos ex-escravos, uniciou a pesquisa portanto antes mesmo do assunto ter se tornado alvo de inquerito civl As terras herdadas em 1867 passaram a ser, na década de 1920 alvo de disputa por colonızadores madeureuros e fazendeıros Fol a partır do marco teirıtorıal desta ação de dıvısão que o INCRA passou a fazer a cadeıa domınıal em 2005, convocando os residentes da area a apresentarem os documentos comprobatórıos de suas propriedades A reação da empresa e alguns proprietarıos que tambem compraram pequenas parcelas dessas terras fol de tentar encobrur o esbulho atraves da alegação de que compraram as terras, e, portanto, passaram a ser seus legítımos donos

Para se defender da ação de regularızação fundıarıa, decıduram contratar um antropologo para fazer um contra-laudo (o proprio prof Silvio fol um dos que recusou a proposta para realizal tal trabalho) Não encontrando facilmente quem aceitasse fazer esse trabalho a empresa contratou um historiador que naquela altura se fez passar por antropologo para legitımar sua versão junto às partes contratantes e seus alıados O relatorio do NUER, e os questionamentos ao contralaudo feitos pelo prof Sílvio foram desconsiderados e o propı 1 Estado silenciou perante o direito dos herdeuros testamentais

Sılvıo já se encontrava doente quando decidıu ur a publico na mesma imprensa que divulgou o assunto para denunciar as estratégıas 
utılizadas para encobrir a fraude O questionamento feito por ele, dos atos que procuravam tornar "legais 'e "legítımas" as terras for recebido com grande desprezo pelo autor do contra-laudo e pela empresa que ja somava apoıos na Câmara e no Senado Federal A saıda encontrada pelo contra-laudo fol inicialmente tentar desmoralızar a pesquisa do NUER, e, depois, desmoralizar o lado mais fraco, identıficado como "quilombola" (nome atrıbuıdo ao direıto a terra na Constıtuıção Federal de 1988) Discursos foram pronunciados e publicados na imprensa local invocando o " desenvolvimento regional" Os herdeiros passaram a sofrer represalıas, a serem descritos como falsárıos interessados em ganhal terras Foram tratados como irresponsaveis por prejudicar o desenvolvimento do município A prefeitura de Campos Novos acatou a demanda desenvolvımentısta do grupo Iguaçu e passou a hostılızar os agricultores negros como baderneiros e de acusa-los de estar espalhando o caos na região De outro lado, invocando a etıca proprıa do exercicıo da antropologıa, Sılvıo Coelho passou a indagar pela formação do profıssıonal que realızou o contra-laudo, a estranhar os métodos utılizados, a questıonar o tremamento que teoricamente habilita o antropólogo como investıgador da cultura Dificilmente um antropologo ra aceitar fornecer atestado de identıdade, como fez o autor do contra laudo, anda mais quando este atestado deduz-se pela não identıdade do grupo, como for este caso A duvida levantada por Silvio sobre o pesquisador contratado pela empresa se detem na analıse do ato de "fazer-se passar por", nisto resıdındo o proprio princípı gestor da versão apresentada para desconstıtuır os direıtos dos herdeiros dos ex-escravos da fazenda Invernada dos Negros de Campos Novos Alem de se fazer passar por antropologo, o historiador contratado pela empresa elaborou um parecer técnico sem ouvir os herdeiros organızados na assocıação comunitárıa Seu argumento central consıstıu em negar a legitumıdade do pleito formulado pelo coletivo de herdeiros dos ex-escravos, apolando, a recem-criada Assocıação dos Legítımos Proprietárıos" Em sua critıca publıca Silvıo põe em dúvida o contra-laudo não somente pelas suas conclusões mas pelo metodo de investıgação distanciado da pesquisa etnografica pratıcada na comunıdade cıentıfıca brasıleıra Em alguma medıda, ele 
baseou sua crítica num tipo de pragmatismo capaz de integrar, num mesmo plano, experiêncıa e julgamento de valor

Foram mais de vinte anos convivendo com Silvio na Universidade Federal de Santa Catarına, mais de vinte anos confirmando aquelas prımeıras ımpressões, reencontrando a confıança quase unabalavel nos pruncipıos étıcos e buscando sempre transcender o seu próprio tempo Hoje, ao reler seus escritos, reencontro ao longo de sua obra, aquela persistêncıa que marcou a sua antropologia o homem (do sul, da aldeıa, da mata, da cıdade) a étıca (do genocídıo, da educação, da clência, do direito)

A escrita etnografica moderna adquurıu status de ciêncıa no centro dos conflıtos e antagonısmos da expansão europeıa, no interıor dos processos de colonızação do mundo Gerıda no interıor de relações e forças desıguaıs, como a da exproprıação, escravıdão e genocıdıo, esta escrita expôs, ao mesmo tempo em que escondeu, as faces mals heroıcas de um estilo produzıdo nas sucessivas conquistas e derrotas da filosofıa da ciência em suas ınumeras tentatıvas de explıcar o mundo, e, nele, o homem

Muito antes de tudo isto, o filósofo Xunzı, que viveu entre 340 a 305 a C , em sua versão surpreendentemente realısta do confucionısmo tomou para si a tarffa de explicar o que muito mais tarde veio a ser incorporado como sendo próprio da antropologıa moderna a dissocıação entre cosmologıa e domínıos etıco-polıtıcos do mundo Xunzı partıu de uma trıade integrada por céu, teıra e homem Nesta trıade de forças em profusão, a tarefa precıpua do homem, sua princıpal característıca serıa provenıente de uma capacıdade de dıstınguu' Caberıa, portanto ao homem não propılamente descobrır o unıverso como ele e, num esforço de conhecimento puro, e portanto vão e inútıl, mas, principalmente, ordena-lo (Cheng 2008 242) Xunzı tenta decifrar esse domínı, perguntando "quando chove depois de se executar a dança da chuva, o que e que isso sıgnıfica?" Para ele, "nada" Ou seja "é exatamente como se chovesse sem que a dança tıvesse sıdo executada Realızar o rito para salvar o sol e a lua dos eclıpses, executar a dança da chuva em período de seca, pratıcar a adıvınhação antes de tomar umportantes decısões, tudo ısso não visa, segundo ele obter aquilo que se pede mas manter viva a cultura' (Cheng, 2008 242)

\section{ILHA}


Com ısto, Xunzı estabelece um novo ato de dıstınção entre natureza e cultura, e o faz para chegar, em seguıda, à ıdeıa de que a cultura é o "fabricado', portanto, e o próprio ato de repartır e ordenar ceu e terra Para Xunzı, € o senso de observação e aprendızagem, ele proprı, um exercicio de inteligência - o que onenta o interesse por esse lado da ' ordem" O homem e suscetıvel de moralıdade por sua capacidade de dıscernumento e ordenação Xunzı parte da ıdeıa de natureza bruta, anımal para a de coração/mente, faculdade especıfıcamente humana de julgar e de atribuir valores, e, com isso, de transformar o ser da natureza em ser étıco A questão da transmissão serıa, portanto, fundamental Ele pergunta "o que e que torna os homens capazes de viver em socıedade?" Sua resposta vai na dıreção do prıncıpıo da partılha, outro gesto de ordenação O que e que faz com que a partılha seja eficaz? Para ele, o senso moral Assım, partılhar em virtude do senso moral leva a harmonia, harmonuzar leva a unidade unuficar leva ao aumento de forças, aumentar as forças leva ao poder, e o poder permite dominar as coisas Todo o pensamento deste filosofo, que antecede as matrızes classıcas maıs conhecıdas da fılosofıa da cıêncıa, chega a noção de que o segredo do sucesso do homem está assocıado ao prıncıpıo de partılha dos recursos e sua hıerarquızação Para Xunzı, o que faz do homem um homem e a sua capacidade de estabelecer distinções, de repartır e partılhar Este pruncípıo de moralıdade reafırmado por Xunzı em toda a sua obra, constıturá a matrız do pensamento confuciano, que aposta no homem e em sua perfectıbılıdade em sua capacıdade de nomear, de cortar e recortar, de estabelecer prıncıpıos de dıvisão, de distınguir entre o semelhante e o diferente, e portanto, uma capacidade de encontrar solução consensual para os conflitos através de alguma leı Toda a teorıa da retıfıcação, dos atos de nomear de Xunzı gıra em torno da ideıa de que conhecer é, na verdade, formular distınções a partir de categorias qualitatıvas preexistentes Segundo Anne Cheng (2008), este autor e um dos que irão, pıoneuramente, juntar epıstemologıa e étıca, fazendo coıncıdır um mesmo prıncípıo de divısão, ao correlacıonar de modo inédıto, experıêncıa e julgamento de valor O pensamento de Xunzı revela toda a complexıdade de sua posıção racıonalısta que irá se revelar adıante como sendo, inclusıve, bastante 
conservadora Este pensamento guarda uma linha de contmuidade com as correntes pragmatıstas ate a atualıdade, não sendo poucas nem infundadas as correlações feıtas entre a antropologıa estrutural e o pensamento classico chinês

O ato de decifrar os modos de ordenação postulados nos mundos em contato na modernıdade untroduzıu sucessıvamente questões já formuladas, que foram, como se vê, com Xunzı, dıscutıdas muıto antes da era crıstã O ato de buscar ıdentıficar a proprıa "essêncıa humana' encontra resposta no dominio etico-político do mundo - o humano como gestor de sı e da sua proprıa alterıdade

A escrita etnográfıca delınela uma untenção, um projeto o de narrar e desvendar modelos de ordenação do mundo, pondo em evidência não somente as cosmologıas, mas o domínı etıco-polıtıco instaurador dos conflitos e das guerras A etnografia, como um campo de conhec1mento que emerge de situações de contato, conflito e guerra, traz em seu arcabouço teorıco o dılema etıco proprıo dos atos de distınguur, ordenar e nomear Como experıêncı/escrita (Geertz, 1997), a etnografia não deıxa de expressar a propria humanıdade que descreve o étıco-polítıco é depreendido dos modelos de ordenação do mundo, daquilo que tem sido apontado cada vez mais como a tarefa precípua do antropólogo e que, não por acaso, o aproxima cada vez mais do legista

Em Avallable Light anthropological refletions on Philosophical Topics, livro traduzıdo e publicado no inícıo deste seculo no Brasıl sob o título Nova luz sobre a Antropologia (2000), Clifford Geertz desenvolve uma reflexão sobre as dimensões étıcas do trabalho de campo antropológıco nos chamados "paises novos" Esse livro, embora muito lido no Brasıl, não tem tıdo qualquer impacto no debate recєnte sobre a responsabılıdade socıal do antropólogo perıto Mas sua importâncıa e megável Nele Geertz dialoga com John Dewey, quando este sustenta que a pesquisa socıal é uma modalıdade de experıêncıa moral, que pensar por sı só ja constıtuı um ato socıal, uma conduta e, portanto, e moralmente julgavel Com base no pragmatısmo de Dewey, Geertz pretende descartar do trabalho do cientısta socıal qualquer possıbılıdade de produzır soluções, diagnóstıcos ou propostas compensatórıas sustentando que o antropólogo quando instado a fazer este trabalho, é 
confrontado com situações sociars cuja solução não parece faculmente alcançavel, ja que não se trata proprıamente de operar um "mulagre técnıco" em uma sıtuação que é do domınıo do polítıco Geertz vaı caracterızar como "ironıa antropológıca" a sıtuação de assımetrıa que esta presente no próprio campo de pesquısa quando falsas expectatıvas de comunhão intercultural vão se desmanchar no momento seguinte, quando as verdadeuras chances de resolução dos conflutos vão ser reveladas, ou quando podem emergır as situações de poderes desıguaıs que a própria situação de pesquisa unstaurou Todo antropólogo que val a campo para um trabalho de pericia se depara logo a seguur com a situação descrita por Geertz

a pressão tanto sobre o pesquisador quanto sobre os seus pesquisados para encararem essas metas como proxımas quando na verdade são distantes como certas quando na verdade meramente desejadas e como alcançadas quando no maxımo houve uma aproxımação delas

Essa pressão, descreve Geertz, derıva da assimetria moral inerente à situação do trabalho de campo, e o que se passa e que a pratica etnografıca expõe em ênfase ou nuanças, dımensões complexas dos nossos proprıos atos moraıs Ele deduz desse dılema a proprı sıtuação do trabalho antropológıco e a sua indıssocıabılıdade que se revela pela pesquisa de campo etnográfıca, ao mesmo tempo em que o trabalho de campo e imprescindível como uma "experiência educatıva completa ' de lidar com limites e fronteiras do eu e do outro, o nos eles

Estou mencionado isto para tentar argumentar que a perícia antropologica não esta dıssocıada dos dılemas postos à etnografıa porque não pode prescindur desta em nenhuma de suas etapas, da experiêncıa à escrita do texto (Leite, 2005) Uma pericia sempre inicia quando o conflıto já esta instaurado Esta tensão moral, atrıbuída à pesquisa, encontra-se de fato no próprıo campo a ser investıgado Talvez a tensão geradora de dilemas etıcos, que tanto Silvio quanto nós vivemos hoje, seja decorrente da consciência propıcıada pela tarefa autoatrıbuıda de narrar e desvendar modelos de ordenação do mundo pois se concentra aí toda a dıfıculdade de ser ao mesmo tempo alguem que está experımentando, interagındo (dentro) e tambem alguem que e observador e ordenador (fora) O ponto dificll de chegar, quase intransponivel para Geertz e a combınação de duas atıtudes em relação à realıdade, a 
engajada e a analitıca, aquela que Silvıo perseguıu em toda a sua vida o tıpo de distanciamento não provém do olhar desınteressado, mas de um tipo de interesse flexível o bastante para suportar uma enorme tensão entre a ação moral e a observação supostamente dıstanciada, uma tensão que só aumenta a medıda que a percepção moral se aprofunda e a propria observação avança Neste sentıdo e que, para Geertz, a fuga para o cientıficısmo ou para o subjetıvismo não passarıa de um mero sinal de que se tentou recorrer a opção mais arrıscada que é a de tentar atıngir a racionalıdade, suprımındo o que há de humano Este é o sınal que para Geertz ındıca maıs as patologıas da clêncıa, do que a sua norma Ou seja, que os dılemas étıcos são "fundacıonaıs" da expenência/escrita etnografica, independente do campo de pesquisa escolhido Portanto, podemos concluir disso que a propalada "crise", ou mesmo, o dilema etıco, dificll de superar para uns mais do que para outros, pode bem ser visto apenas como "ironia", mass uma evidencia da indissociavel assimetria que nos conforma como humanos

\section{Referêncıas biblıográficas}

CHENG Anne Xunzı herdeiro realista de Confucio In ___ Historia do pensamento chinês Tradução de Gentıl Avelıno Titton Petropolıs RJ Vozes, 2008 p 236261

GEERTZ Clifford O saber local Petropolıs RJ Vozes 1997

GEERTZ Clifford Nova luz sobre a antropologia Rıo de Janeiro Zahar 2000

LEITE Ilka B Os laudos periciais um novo cenario na pratica antropologı ca In LEITE Ilka B (Org) Laudos antropologicos em debate Flonanopolis NUER/UFSC ABA 2005 p 1328

NUCLEO DE ESTUDOS SOBRE IDENTIDADE E RELAÇÕES INTERETNI CAS (NUER) Quilombos no Sul do Brasil pericias antropologicas Bole ttm Informattvo do NUER Florianopolis v 3 n 32006

SANTOS Silvio Coelho dos et al Projeto Urugual consequências da constru ção da barragem Machadınho para os ındıos do PI Ligeıro (RS) Florıa nopolis Ed da UFSC FAPEU ELETROSUL FUNAI 1980 Relatorio de Consultoria

SANTOS Sulvio Coelho dos Construção de barragens e sociedades indıgenas no Sul do Brasil America Indigena, Mexico v 43 n 2 p 3193421983

SANTOS Silvio Coelho dos Os povos indigenas e a Constituinte Porto Alegre Movimento, Florianopolis Ed da UFSC 1989

SANTOS Silvıo Coelho dos Ensalos oportunos Florianopolıs Academia Cata rinense de Letras 2007 